Danijela Nikolić ${ }^{1}$ Saša Jovanović Jasmina Skerlić Vanja Šušteršič Jasna Radulović

\section{METHODOLOGY OF LIFE CYCLE SUSTAINABILITY ASSESSMENT}

Abstract: Life Cycle Assessment (LCA) represents the most widely adopted tool for calculation and evaluation of the environmentally relevant inputs and outputs and the potential environmental impacts of the life cycle of a product, material or service. But, LCA methodology has its own disadvantages: it assesses environmental sustainability impacts and neglects the social and economic aspect of sustainability. Over the past decade, LCA has improved to include life cycle costing (LCC) and social LCA (SLCA), drawing on the 'triple bottom line' model of sustainability. With these developments, LCA has broadened from merely environmental assessment to a more comprehensive life cycle sustainability assessment. This paper presents the concepts and methodologies for developing the sustainability method based on life cycle thinking, including a description of a new method called Life Cycle Sustainability Assessment (LCSA). It was described the concept of sustainability, with three pillars of sustainability, i.e. the environmental, economic and social dimensions, which is the basement of LCSA methodology. After that the indicators were presented, as a ways of measuring impacts which indicate changes away from an original or a wanted condition.

Keywords: sustainability, life cycle sssessment (LCA), life cycle sustainability assessment (LCSA), indicator.

\section{Introduction}

Methodology of Life Cycle Assessment (LCA) was developed over the past 45 years as an analytical tool to measure and evaluate the environmental impacts of products and services (Schwarz, 2017) and it is essential to sustainable development, as it involves the evaluation of the environmental impacts of a product system through all stages of its life cycle (Hertwich, 2005; European Commission 2003). The main goals of life cycle assessment are to reduce a product's resource use and emissions to the environment. The results of a Life Cycle Assessment can provide substantial information for decision-making in product development, ecodesign and the design of (manufacturing) processes on a corporate level, as well as for consumer decisions at the consumer level (Koroneos at al, 2013).

The first LCA studies that are now recognised as (partial) LCAs date from the late 1960s and early 1970s, a period in which environmental issues like resource and energy efficiency, pollution control and solid waste became issues of broad public concern.

Over the past decade, LCA has broadened to also include life cycle costing (LCC) and social LCA (SLCA), drawing on the three-

\footnotetext{
${ }^{1}$ Corresponding author: Danijela Nikolic Email: danijelan@kg.ac.rs
} 


\section{DIFSIFAIDQ}

pillar or 'triple bottom line' model of sustainability (Clift \& Druckman, 2015). With these developments, LCA has broadened from merely environmental assessment to a more comprehensive life cycle sustainability assessment (LCSA).

There are three dimensions along which LCSA is expanding when compared to environmental LCA: (1) broadening of impacts, LCSA = LCA + LCC + SLCA; (2) broadening level of analysis, product-, sector- and economy-wide questions and analyses and (3) deepening, including other than just technological relations, such as physical, economic and behavioural relations.

From this analysis, it is clear that the vast majority of LCSA research so far has focused on the 'broadening of impacts' dimension only.

\section{Sustainability}

The concept of sustainability finds its origin in the forestry sector at XVIII century. Today, there are more than 300 definitions which have been formulated since the Brundtland report (Johnston, et al. 2007), and the spread of terms and definitions has increased according to different sources and authors (Schwarz, 2017).

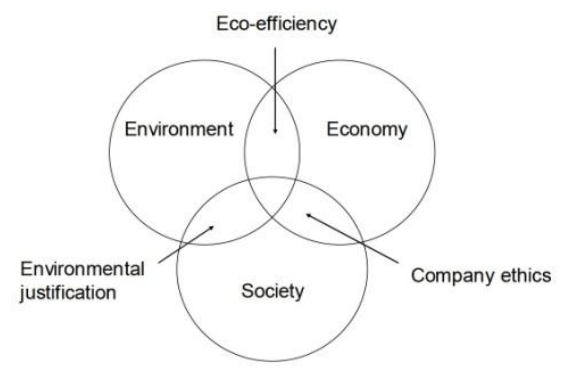

Figure 1. Three pillars of sustainability

The idea of sustainability evolves around the concern for the anthropological impacts on the Earth's ecosystem, but simultaneously includes both a social and an economic dimension. Based on this fact Elkington introduced the concept of the Triple Bottom Line (TBL) of sustainability in 1994 (Elkington, 1997). It states that sustainability should be measured against three dimensions: environment, economy and society, as showed in Figure 1.

It is not easy to define in unique way each pillar of sustainability, but it can be defined as next (Valente, 2013):

- environmental sustainability is the capacity to preserve rates of renewable resource harvest, pollution creation, and nonrenewable resource depletion indefinitely;

- economic sustainability is the capacity to maintain a definite level of economic production indefinitely;

- $\quad$ social sustainability is the capacity of a social system to operate at a definite level of social well-being indefinitely.

According to the concept of the TBL, a focus on the environmental impacts and economic outcomes of an industrial activity is not sufficient to guarantee sustainability in the long run. Instead, it is of vital importance to include the social aspect, such as justice and distribution of assets both between individuals and companies, as well as between generations (Hauschild, 2005).

The hugely influential Brundtland Report (WCED, 1987) states that "sustainable development is development that meets the needs of the present without compromising the ability of future generations to meet their own needs". This definition of sustainable development is the most generally accepted, commonly cited definition for sustainability as a whole.

The most developed frameworks assessing product sustainability is situated at the intersection of the environment and economy, adressing almost exclusively the 
aspect of eco-efficiency (Shuaib at al, 2014). In addition, concepts accounting for social or economic sustainability have been developed and find application in industry and the public sector.

\section{Concept and Methodology of LCSA}

Life Cycle Sustainability Assessment method is result of the effort from UNEP/SETAC Life Cycle Initiative for extending the original scope of LCA towards sustainability assessment (UNEP/SETAC, 2009). Hence, the life cycle tool can be used for assessing the sustainability of products and process systems. LCSA is a developing method for "evaluating all environmental, social and economic negative impacts and benefits in decision-making processes towards more sustainable products throughout their life cycle" (UNEP/SETAC, 2011).

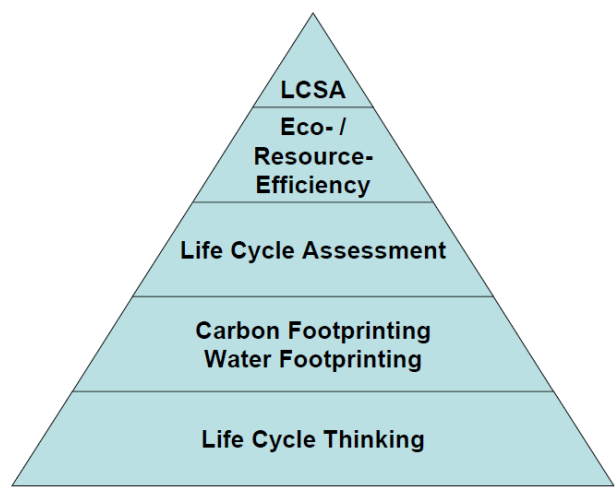

Figure 2. Pyramid of the methodological development of LCSA

LCSA comes from the life cycle thinking approach and it can be represented graphically as a pyramid (Figure 2) according to Finkbeiner et al. (2010). On the bottom of the pyramid, life cycle thinking is the qualitative aspect and on the level above it begins developing into quantitative concepts such as carbon and water footprinting methods. LCA is the next level where more environmental aspects are considered at the same time. Higher in the pyramid, eco-efficiency and resource efficiency assessments include environmental and economic indicators at the same time. The last level is LCSA, where even the social dimension is included in the assessment.

The first theoretical idea guiding the current LCSA approach came from the German Oeko-Institut in 1987. Kloepffer (2008) has proposed a formula for LCSA, where three methods i.e. Life Cycle Assessment (LCA), Life Cycle Costing (LCC) and Social Life Cycle Analysis (SLCA) are summed:

$$
\mathrm{LCSA}=\mathrm{LCA}+\mathrm{LCC}+\mathrm{SLCA}
$$

The LCC method has been developed independently and before the LCA and it represents the economic counterpart of LCA together with Full Cost Accounting (FCA) or Total Cost Assessment (or Accounting) (TCA). LCC is directly linked to the life cycle of a product system for assessing the true costs to be compared with another one having the same function. In some cases, the LCA of a product may be longer that the economic life cyle.

Social LCA is a more recent methodology than LCA and LCC. It is an emerging tool for measuring the social impact of product. The scope of the S-LCA is "to promote improvement of social conditions and of the overall socio-economic performance of a product throughout its life cycle for all of its stakeholders" (UNEP/SETAC 2009). As in the case of LCC, S-LCA have similarities and differences with LCA. In S-LCA, e.g. the geographical dimension is very important, because social issues are different from country to country. The time frame is another key element, because social impacts changes over time.

These three tools should be considered as three ways of looking at the same system. 
Abbreviation of LCSA is used also for indicating another method called Life Cycle Sustainability Analysis as proposed by Guinee et al. (2011). This method advises an integrated framework at a conceptual level which is different than the LCSA method of Kloepffer (2008). Kloepffer models separately each aspect of sustainability and in the end of the analysis the method proposes a synthesis of the results for a final decision. However, Guinee's approach is only theoretical and there are not operational examples.

A new guideline towards LCSA standardization was made by SETAC and UNEP (2011). According to these guidelines, the benefits of using LCSA are that you are able to (Valente at al. 2013):

- show a balance between the three dimensions of sustain-ability, life cycle stages and impacts, products and generations;

- show enterprise to be more responsible environmentally and socially;

- support sustainability consciousness along value chain actors;

- help value chains actors in finding out weak points of product life cycle;

- support decisions makers in choosing sustainable products and in giving priority to resources with less negative impacts;

- promote innovation and help to increase credibility in enterprises and suppliers and

- inform labeling projects.

Methodology of LCSA should follow the same steps as the ISO 14040 series, i.e. goal and scope definition, inventory analysis, impacts assessment and interpretation. LCA is ISO standardized through the ISO series 14040:14044, LCC is ISO standardized for building materials only and has a code of practice (Swarr et al. 2011), while S-LCA has guidelines only (UNEP/SETAC 2009).
The current status of LCSA shows different grades of maturity for the three methodologies. While assessment of the environmental aspects is based on well known and established methodologies, the methods for evaluating economic and social aspects are under development.

\section{LCSA indicators}

The explanation of indicators are varies in different scientific fields. Indicators are a way of measuring impacts and indicate changes away from an original or a wanted condition: "Indicators have the capacity to summarize, focus and condense the complexity of dynamic environment to a manageable amount of meaningful information. By visualizing phenomena and highlighting trends, indicators simplify, quantify, analyze and communicate otherwise complex and complicated information" (Singh et al. 2009). In respect to each dimension of sustainability (environmental, economical and social), the indicators are shown both in an extensive overview and in a more selective one.

Environmental indicators connected to LCA are: Abiotic resource depletion potential, Biotic resource depletion potential, Primary Energy Demand, Global warming potential, Acidification potential, Eutrophication potential, Ozone depletion potential, Photochemical ozone creation Potential, Human- and eco-toxcity, Particulate matter formation, Land use and Water use (Schwarz, 2017). In addition to the quantitative environmental indicators, there are several environmental aspects which are not that easily quantified.

Specific economic indicators are recommended by the UNEP/SETAC guidelines for LCSA and other literature (Valente, 2013) Table 1. However, there is possibility to time limitation, controversy of some indicators and "double counting" issues between some social and economic indicators. 
Table 1. Economic indicators

\begin{tabular}{|c|c|c|}
\hline & Cost categories & Indicators \\
\hline \multirow{7}{*}{$\begin{array}{c}\text { UNEP/SETAC } \\
2011\end{array}$} & Labour costs & Wages costs \\
\hline & \multirow{6}{*}{ Material costs } & Material costs (operational costs) \\
\hline & & Energy costs (operational costs) \\
\hline & & Equipment costs (investment costs) \\
\hline & & Revenues \\
\hline & & Taxes \\
\hline & & Discount analysis \\
\hline \multirow{8}{*}{$\begin{array}{c}\text { Basurko and } \\
\text { Mesbahi, } 2012\end{array}$} & \multirow{6}{*}{ Annual capital charge } & Capital costs \\
\hline & & Interest rate \\
\hline & & Repayment period \\
\hline & & Consumables costs \\
\hline & & Training costs \\
\hline & & Maintenance Costs \\
\hline & \multirow[b]{2}{*}{ End-of-life costs } & End-of-life costs \\
\hline & & $\begin{array}{l}\text { Number of years between present and } \\
\text { future time }\end{array}$ \\
\hline
\end{tabular}

List of indicators most used in social LCA study by several authors and organizations, includes the next social indicators: Total number of employees, for type of contract, measured of diversity and type of work; Average salary of workers; Valorization of the diversity; Health and safety of working conditions; Professional development and employability; Company committment for improving environmental quality; Child labour; Forced and compulsary work; Marketing policy; Knowledge and management of potential damage of products and services; Practice against corruption and illegal price fixing and Freedom of association and collective bargaining.

In the social science field, it is very important to interact with the project partners, companies and stakeholder since social issue are evaluated not only quantitatively, but also qualitatively. It is to highlight that sometimes social indicators can be defined also as socio-economic indicators, due to the strong interaction between these two spheres and so it is difficult to have a clear distinction.

\section{Conclusion}

Big chalenge for scientist was to develop a framework for sustainability life cycle assessment, because of the innovative and recent methodology and lack of standards. A new method called Life Cycle Sustainability Assessment can be a solution to this problem. This method allows evaluating the three pillars of sustainability, using the methodology of LCA, LCC and S-LCA. Even if these methodologies have different level of maturity (from the well-known LCA to the recent and not very developed Social LCA), it is possible to assess products along the supply chain.

LCSA is the most developed sustainability approach today, even if only a few examples of application are currently available and few of them include social aspects. The methodology has been criticized of lacking the understanding of the interdependency between the three pillars of sustainability . However, it is a comprehensive approach and the most accepted method internationally. 
Acknowledgment: This investigation is part of the project TR 33015 of Technological Development of the Republic of Serbia. The authors like to thank to the Ministry of
Education and Science of Republic of Serbia for the financial support during this investigation.

\section{References:}

Clift R.\& Druckman A., (2015), Taking Stock of Industrial Ecology, Springer, ISBN 978-3319-20570-0, doi: 10.1007/978-3-319-20571-7

European Commission (2003). Towards a Thematic Strategy on the Sustainable Use of Natural Resources. Communica

Finkbeiner M., Schau E. M., Lehmann A. and M. Traverso. (2010). Towards Life Cycle Sustainability Assessment. Sustainability 2 (10)): p.3309-3322

Guinée, J. B., R. Heijungs, G. Huppes, A. Zamagni, P. Masoni, R. Buonamici, T.Ekvall, and T. Rydberg. (2011). Life Cycle Assessment: Past, Present, and Future. Environmental Science \& Technology 45 (1): p. 90-96.

Hauschild M., Jeswiet J. and L. Alting. (2005). From Life Cycle Assessment to Sustainable Production: Status and Perspectives. CIRP Annals - Manufacturing Technology, 54 (2): p. 121

Hertwich E. (2005). Life cycle approaches to sustainable consumption: a critical review. Environmental Science \& Technology 39 (13): p. 4673.

J. Elkington. (1997). Partnerships from Cannibals with Forks: The Triple Bottom line of 21st Century Business. Environmental Quality Management (199): p. 37-51

Johnston P., Everard M., Santillo D. and Karl-Henrik R.. (2007)., Reclaiming the Definition of Sustainability (7 Pp). Environmental Science and Pollution Research - International 14 (1): p. 60-66.

Kloepffer W. (2008). Life Cycle Sustainability Assessment of Products. The International Journal of Life Cycle Assessment 13 (2): p. 89-95

Koroneos C., Nanaki E., Rovas D., Krokida M. (2013), Life Cycle Assessment: A Strategic Tool for Sustainable Development Decisions, The 3rd world sustainability forum

Schwarz I. (2017), Beyond LCA: Development of a framework for product sustainability assessment in the context of a product's system environment, Master Thesis, MIT Massachusetts Institute of Technology

Shuaib M., Seevers D., Zhang X., Badurdeen F., Rouch K. E., and Jawahir I. S.. (2014). Product sustainability index (ProdSI): A metrics-based framework to evaluate the total life cycle sustainability of manufactured products. Journal of Industrial Ecology, 18 (4): p. 491507

Singh R. K., Murty H.R, Gupta, S.K. and. Dikshit A.K. (2009). An Overview of Sustainability Assessment Methodologies. Ecological Indicators 9 (2): p. 189-212

Swarr, T. E., Hunkeler D., Klöpffer W., Pesonen H.L., Ciroth A., Brent A. C. and Pagan R.. (2011). Environmental Life-Cycle Costing: A Code of Practice. The International Journal of Life Cycle Assessment 16 (5): p. 389-391

UNEP/SETAC. (2009). Guidelines for Social Life Cycle Assessment of Products. UNEP/SETAC LIfe Cycle Initiative

UNEP/SETAC. (2011). Towards a Life Cycle Sustainability Assessment: Making Informed Choices on Products

Valente C., Saur Modahl I. and Askham C., (2013). Method development for Life Cycle Sustainability Assessment (LCSA) of New Norwegian Biorefinery - Report, ISBN 978-82- 
7520-711-9

W. WCED. (1987). Report of the World Commission on Environment and Development: Our Common Future Acronyms and Note on Terminology Chairman's Foreword

\section{Danijela Nikolić}

Faculty of engineering

University of Kragujevac,

Kragujevac,

Serbia

danijelan@kg.ac.rs

\section{Vanja Šušteršič}

Faculty of engineering

University of Kragujevac,

Kragujevac,

Serbia

vanjas@kg.ac.rs

\section{Saša Jovanović}

Faculty of engineering

University of Kragujevac,

Kragujevac,

Serbia

dviks@kg.ac.rs

\section{Jasna Radulović}

Faculty of engineering

University of Kragujevac,

Kragujevac,

Serbia

jasna@kg.ac.rs

\section{Jasmina Skerlić}

Faculty of engineering

University of Kragujevac,

Kragujevac,

Serbia

jskerlic@kg.ac.rs 


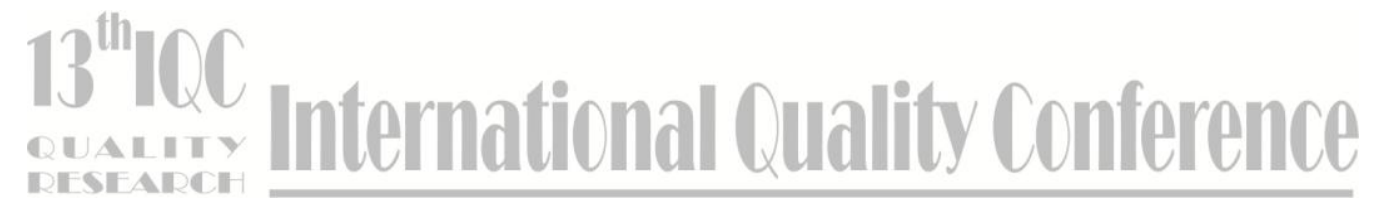

